\title{
Expression of concern: Short hairpin RNA (shRNA) of type 2 interleukin-1 receptor (IL1R2) inhibits the proliferation of human osteosarcoma U-2 OS cells
}

\author{
Xiwei Liu ${ }^{1} \cdot$ Li Min $^{1} \cdot$ Hong Duan $^{1} \cdot$ Rui Shi $^{1} \cdot$ Wenli Zhang ${ }^{1} \cdot$ Song Hong ${ }^{1} \cdot$ Chongqi Tu$^{1}$
}

Published online: 17 August 2018

(c) Springer Science+Business Media, LLC, part of Springer Nature 2018

\section{Expression of Concern: \\ Med Oncol (2015) 32:364 \\ https://doi.org/10.1007/s12032-014-0364-2}

Concerns have been raised about this article [1] relating to the appropriateness of the use of the shRNA (5'-GCGGAG GGTTTGAAAGAATATCTCGAGATATTCTTTCAAACC CTCCGCTTTTTT-3') as a non-targeting control and similarities in text and formatting with other published articles. This is currently under investigation and appropriate editorial action will be taken once the investigation is concluded.
The authors did not respond to our correspondence regarding this expression of concern.

\section{Reference}

1. Xiwei Liu L, Min H, Duan R, Shi W, Zhang S, Hong C, Tu. Short hairpin RNA (shRNA) of type 2 interleukin-1 receptor (IL1R2) inhibits the proliferation of human osteosarcoma U-2 OS cells. Med Oncol. 2015;32:364.
The online version of the original article can be found under https ://doi.org/10.1007/s12032-014-0364-2.

Chongqi Tu

chongqitu@163.com

1 Department of Orthopedics, West China Hospital, Sichuan University, Guoxue Xiang 37\#, Chengdu 610041, China 